\title{
Pathophysiology of Covid-19
}

\author{
Mini Review
}

Volume 3 Issue 2- 2022

\author{
Author Details \\ Mohammad Yavari ${ }^{1}$, Maryam sanei ${ }^{2}$, Alex avakian ${ }^{3}$, Parand Danafar $^{4}$, Aidin Mahmoudi Azar 5 , Hossein \\ Esmaeili6 * \\ ${ }^{1}$ Bachelor of Science in Nursing, Islamic Azad University Tehran Branch, Tehran, Iran \\ ${ }^{2}$ Faculty of medicine, medical university of isfahan, isfahan, iran \\ ${ }^{3}$ Department of Medicine, Islamic Azad University Sari branch, Sari, Iran \\ ${ }^{4}$ Department of Medicine, Islamic Azad University Kashan Branch, Kashan, Iran \\ ${ }^{5}$ Department of Scientific Research Subject Management Imam Ali University of Tehran \\ ${ }^{6}$ Medical Student, Department of Medicine, Islamic Azad University Tehran Medical Sciences, Tehran, Iran
}

*Corresponding author

Hossein Esmaeili, Medical Student, Department of Medicine, Islamic Azad University Tehran Medical Sciences, Tehran, Iran Article History

Received: January 20, 2022 Accepted: January 31, 2022 Published: February 02, 2022

\begin{abstract}
In late 2019, in late December, a virus now called SARS-CoV-2 caused unusual respiratory illnesses in Wuhan, Hubei Province, China. The disease was called COVID-19. The virus is contagious to humans and has caused a worldwide outbreak. Acute kidney disease (AKI) is found in 5 to $15 \%$ of cases of SARS-CoV and MERS-CoV infection, and according to recorded statistics, the mortality rate is approximately higher. 60 to 90\%. Controversial data on the adverse effects of PPI and COVID-19, which were positively evaluated with famotidine under pharmacological observations for GI treatments in COVID-19 patients. Severe myocardial injury, as Increased levels of cardiac biomarkers or electrocardiogram abnormalities were detectable in 7 to $20 \%$ of patients with Covid 19 in the first studies in China.
\end{abstract}

Keywords: Covid-19; Effect of Covid-19; Heart Covid-19; Pathophysiology Covid-19

\section{Introduction}

After this respiratory viral illness had it's first case representation in Wuhan, China back in December 2019, SARS-CoV-2 was dispersed widely soon after inasmuch as bringing about a declaration of a global pandemic on March 2020 by World Health Organization (WHO) [1].

While among the first cases, myocardial damage with increased cardiac biomarkers had a dominant outlook, a study of 138 COVID-19 patients in Wuhan, indicated a 7.2 percent of cardiac failure with high sensitivity Troponin I (hs-cTnI) and ECG abnormalities among the total patients with $22 \%$ of them needing an intesive care [2].

Another example reports a 63 year-old chinese male without a known past medical history of cardiac disease whome approached with severe respiratory symptoms; had acute myocarditis, left ventricle enlargement (with $6,1 \mathrm{~cm}$ end diastolic dimention) and decreased ejection fraction followed by increased troponin-1 (>11 ng/ml) and higher NT-proBNP (> 22,000 pg/ml) levels. Although Glucocorticoid is not recommended because of it's uncertain therapeutic effects, Due to this patient's condition of cardiogenic shock; steroids were applied followed by ECLS, IV immunoglobulin and antiviral medicine as his treatment. As a result, ventricular function had a significant improvement within 2 weeks [3]. The World Health Organization does not recommend glucocorticoid therapy because the effect will remain after this type of treatment $[4,5]$.

AKI was associated with severe combined events in Weak 19 and was one of the leading causes of death, requiring intensive care in the ICU of Quid 19 patients. This association was not significantly influenced by gender, age, cardiovascular disease, diabetes, chronic obstructive pulmonary disease, and CKD [6].

It should be noted that RNA SARS-CoV-2 was seen and identified in the stool sample of the first patient with Covid 19 in the United States., raising the concern for fecal-oral transmission of the virus. The virus components found in the fecal sample may have been from infectious enterocytes of the patient's ileum and colon. As previously mentioned, 
the expression of ACE2 on intestinal enterocytes makes both the small and large intestines susceptible to SARS-CoV-2 infection [7-10]

\section{Corona Virus has Destructive Effects on the Gastrointestinal Tract}

Early reports all based on retrospective data from China, reported the prevalence of GI symptoms in COV-ID-19 cases between 11.4 and $50 \%[11,12]$. In an extensive analysis of 4,000 patients, we found that the prevalence of gastrointestinal symptoms was $17 \%$ [13] Gastrointestinal symptoms are one of the first signs of COVID-19 infection, reported in 3 to $10 \%$ of adult patients and most children. Severe diarrhea is one of the most serious gastrointestinal symptoms of COVID-19, although most of the symptoms are often in the upper gastrointestinal tract. It is abundant in the general population and requires a standard approach with proton pump inhibitors (PPIs) or $\mathrm{H}_{2}$ receptor antagonists $\left(\mathrm{H}_{2} \mathrm{RAs}\right)$. The observation of an ap- parent clinical benefit with famotidine in COVID-19 patients, who were taking the drug for acid-related reflux, prompted a small study which reported an improved clinical outcome in COVID-19 patients [14], further confirmed in a propensity score matched retrospective cohort study [15]. The Considerable observations concerning negative effects of PPI use and COVID-19 and these positive results with famotidine are addressed under pharmacotherapeutic considerations for GI treatments in COVID-19 patients. Loss of appetite (anorexia), nausea, vomiting, and abdominal pain may be symptoms of the upper gastrointestinal tract. The most commonly reported symptom is anorexia, although it is completely nonspecific. Fatigue associated with SARS-Cov-2 infection, as well as the need for various medications, which may include feverfew, painkillers, antibiotics, etc. Neurosensory effects such as dysgeusia and anosmia are most of the time reported in patients with a mild clinical course [16]. And may contribute to anorexia as well as nausea. Direct functional damage to the gastrointestinal tract due to viral interaction with the squamous and columnar epithelium is mediated by ACE2 receptor interference. However, the expression of ACE2 receptors is signify COVID-19 and GI Disease It is not present in the esophagus and stomach compared to the intestine or it is very low. Less observation in the esophagus and stomach compared to the intestinal mucosa also applies to the serine protease complex TMPRSS2.In the absence of prospective endoscopic studies, reliable data on the prevalence of peptic ulcer and its complications are not available. Endoscopy should be considered for patients with bleeding. Medical management of indigestion symptoms should rely on standard treatments [17-20].

\section{Covid 19 Lurks in People with Cardiovascular Disease}

\section{Myocardial injury and myocarditis}

Acute myocardial injury, as evidenced by elevated levels of cardiac biomarkers or electrocardiogram abnormalities, was observed in $7-20 \%$ of patients with COVID-19 in early studies in China [21-26]. The presence of myocardial injury was associated with a significantly worse prognosis [27]. In a report of 41 patients with Quid 19 in Wuhan, five patients had high-sensitivity myocardial injury with high levels of cardiac troponin $(>28 \mathrm{pg} / \mathrm{ml})$, four of whom were admitted to the ICU [21]. In a multicentre cohort study of 191 patients with COVID-19, 33 patients (17\%) had acute cardiac injury, of whom 32 died [24]. In a subsequent study of 416 patients hospitalized with COVID-19, 82 patients $(20 \%)$ had evidence of cardiac injury, which was associated with a 5 -fold increase in the need for invasive mechanical ventilation and an 11-fold increase in mortality [27]. Of note, cardiac injury was found to be an independent risk factor for in-hospital mortality [27]. Another study confirmed this finding and reported that the rate of death in patients with elevated levels of cardiac troponin $\mathrm{T}$ was $37.5 \%$, whereas, in patients with underlying cardiovascular comorbidities plus elevated levels of cardiac troponin T, it was almost double (69.4\%) [28]. Furthermore, a subsequent study demonstrated that markers of myocardial injury were predictive of the risk of in-hospital mortality in patients with severe COVID-19 [29]. The lower part of the function index curve of the primary level of cardiac troponin I receptor for predicting in-hospital mortality was 0.92 . Other factors predicting myocardial injury, such as old age, the presence of underlying disease, etc are also influential.

\section{Cardiovascular effects of antiviral drugs}

At present, many research teams worldwide are focused on the development of drugs for the prevention and treatment of COVID-19 [30]. Of note, the development and testing of new drugs are time-consuming processes [31] and not a viable strategy during this COVID-19 pandemic. Drug repurposing [31], in which existing medications that have already been approved for a disease are tested for a new condition, is currently the main approach in the search for new drugs for COVID-19 [30,32-34]. However, some of the drugs under investigation have known or unknown cardiovascular adverse effects [35] or might be involved in drug-drug or drug-disease interactions [30,32].

\section{Covid-19 Communication with Kidney}

Epidemiological data show that the incidence of severe coronary heart disease is 19 to 25 percent. Even if the lungs and major organs are damaged, the kidneys are one of the most severely damaged organs [36]. Acute kidney injury (AKI) was seen in $5-15 \%$ of the cases infected with SARS-CoV and MERS-CoV and had a higher mortality rate of $60-90 \%$ as per the literature [37]. COVID-19 infection causes AKI and is an independent risk factor for mortality [38,39]. Covid 19 also affects patients with chronic kidney disease (CKD), patients undergoing chronic replacement therapy, and kidney transplant patients. Mohammad et al. Evaluated the causative factors (AKI) in 161 patients admitted to the intensive care unit. In this study, 28\% incidence of AKI was observed. Approximately 35\% of the patients who developed AKI had a history of CKD stages 3-5 Twenty-eight percent of the patients with CKD stages 3 - 5 had no AKI [40].

In the patients who developed AKI from COVID-19 infection, around $1.5-9 \%$ of them required RRT in the form of CRRT [41,42]. The proportion of patients needing RRT increased to $5.2-25 \%$ with severe infection $[43,44]$. According to international researchers and experts, in severe cases of Covid-19 with hypoxemic respiratory failure with renal and hepatic impairment, ECMO can be used with or without CRRT. The most widely used method of blood purification in clinical practice is CRRT, but for severe COVID-19 patients with sepsis and ARDS, hemoperfusion/plasma adsorption treatment can also be selected to clear more inflammatory mediators [45].

Recommendations on the care of hospitalized patients with COVID-19 and kidney failure needing RRT from the American Society of Nephrology (ASN) was summarized below [46].

\section{Conclusion}

In this article, we tried to examine the different effects of the corona virus. Studies show that coronavirus can have significant effects on the digestive system, cardiovascular system and kidneys.

\section{References}

1. Cascella M, Rajnik M, Aleem A, Dulebohn SC, Napoli RD (2021) Features, evaluation, and treatment of coronavirus (COVID-19). StatPearls.

2. Dawei W, Hu B, Hu C, Zhu F, Liu X, et al. (2020) Clinical characteristics of 138 hospitalized patients with 2019 novel coronavirus-infected pneumonia in Wuhan, China. Jama 323(11): 1061-1069.

3. Zeng JH, Liu YX, Yuan J, Wang FX, Wu WB, et al. (2020) First case of 
COVID-19 complicated with fulminant myocarditis: a case report and insights. Infection 48(5): 773-777.

4. Centers for Disease Control and Prevention (2020) Interim clinical guidance for management of patients with confirmed coronavirus disease (COVID-19).

5. Askin L, Tanrıverdi O, Askin HS (2020) The effect of coronavirus disease 2019 on cardiovascular diseases. Arquivos brasileiros de cardiologia 114(5): 817-822.

6. Yarijani ZM, Najafi H (2021) Kidney injury in COVID-19 patients, drug development and their renal complications: Review study. Biomedicine Pharmacotherapy 142: 111966

7. Holshue ML, DeBolt C, Lindquist S, Lofy KH, Wiesman J, et al. (2020) First case of 2019 novel coronavirus in the United States. New England Journal of Medicine 382(10): 929-936.

8. Du M, Cai G, Chen F, Christiani DC, Zhang Z, et al. (2020) Multiomics evaluation of gastrointestinal and other clinical characteristics of COVID-19. Gastroenterology 158(8): 2298-2301.

9. Zhang H, Kang Z, Gong H, Xu D, Wang J, et al. (2020) The digestive system is a potential route of $2019-\mathrm{nCov}$ infection: a bioinformatics analysis based on single-cell transcriptomes. BioRxiv.

10. Cha MH, Regueiro M, Sandhu DS (2020) Gastrointestinal and hepatic manifestations of COVID-19: A comprehensive review. World journal of gastroenterology 26(19): 2323-2332.

11. Jin X, Lian JS, Hu JH, Gao J, Zheng L, et al. (2020) Epidemiological, clinical and virological characteristics of 74 cases of coronavirus-infected disease 2019 (COVID-19) with gastrointestinal symptoms. Gut 69(6): 1002-1009.

12. Pan L, Mu M, Yang P, Sun Y, Wang R, et al. (2020) Clinical characteristics of COVID-19 patients with digestive symptoms in Hubei, China: a descriptive, cross-sectional, multicenter study. The American journal of gastroenterology 115(5): 766-773.

13. Cheung KS, Hung IFN, Chan PPY, Lung KC, Tso E, et al. (2020) Gastrointestinal manifestations of SARS-CoV-2 infection and virus load in fecal samples from a Hong Kong cohort: systematic review and metaanalysis. Gastroenterology 159(1): 81-95.

14. Janowitz T, Gablenz E, Pattinson D, Wang TC, Conigliaro J, et al. (2020) Famotidine use and quantitative symptom tracking for COVID-19 in non-hospitalised patients: a case series. Gut 69(9): 1592-1597.

15. Freedberg DE, Conigliaro J, Wang TC, Tracey KJ, Callahan MV, et al. (2020) Famotidine use is associated with improved clinical outcomes in hospitalized COVID-19 patients: a propensity score matched retrospective cohort study. Gastroenterology 159(3): 1129-1131.

16. Levinson R, Elbaz M, Ben-Ami R, Shasha D, Levinson T, et al. (2020) Anosmia and dysgeusia in patients with mild SARS-CoV-2 infection. MedRxiv.

17. Hoffmann M, Kleine-Weber H, Schroeder S, Krüge N, Herrler T et al. (2020) SARS-CoV-2 cell entry depends on $\mathrm{ACE}_{2}$ and TMPRSS ${ }_{2}$ and is blocked by a clinically proven protease inhibitor. Cell 181(2): 271-280.

18. Zhang H, Kang Z, Gong H, Xu D, Wang J, et al. (2020) Digestive system is a potential route of COVID-19: an analysis of single-cell coexpression pattern of key proteins in viral entry process. Gut 69(6): 1010-1018.

19. Barbry P, Muus C, Luecken M, Eraslan G, Waghray A, et al. (2020) Integrated analyses of single-cell atlases reveal age, gender, and smoking status associations with cell type-specific expression of mediators of SARS-CoV-2 viral entry and highlights inflammatory programs in putative target cells.

20. Hunt RH, East JE, Lanas A, Malfertheiner P, Satsangi J, et al. (2021) COVID-19 and Gastrointestinal Disease: Implications for the Gastroenterologist. Digestive Diseases 39(2): 119-139.

21. Huang C, Wang Y, Li X, Ren L, Zhao J, et al. (2020) Clinical features of patients infected with 2019 novel coronavirus in Wuhan, China. The lancet 395(10223): 497-506.
22. Wang D, Hu B, Hu C, Zhu F, Liu X, et al. (2020) Clinical characteristics of 138 hospitalized patients with 2019 novel coronavirus-infected pneumonia in Wuhan, China. Jama 323(11): 1061-1069.

23. Zhou F, Yu T, Du R, Fan G, Liu Y, et al. (2020) Clinical course and risk factors for mortality of adult inpatients with COVID-19 in Wuhan, China: a retrospective cohort study. The lancet 395(10229): 1054-1062.

24. Zhou F, Yu T, Du R, Fan G, Liu Y, et al. (2020) Clinical course and risk factors for mortality of adult inpatients with COVID-19 in Wuhan, China: a retrospective cohort study. The lancet 395(10229): 1054-1062.

25. Wu Z, McGoogan JM (2020) Characteristics of and important lessons from the coronavirus disease 2019 (COVID-19) outbreak in China: summary of a report of 72314 cases from the Chinese Center for Disease Control and Prevention. Jama 323(13): 1239-1242.

26. Nishiga M, Wanget DW, Han Y, Lewis DB, Wu JC (2020) COVID-19 and cardiovascular disease: from basic mechanisms to clinical perspectives. Nature Reviews Cardiology 17(9): 543-558.

27. Shi S, Qin M, Shen B, Cai Y, Liu T, et al. (2020) Association of cardiac injury with mortality in hospitalized patients with COVID-19 in Wuhan, China. JAMA cardiology 5(7): 802-810.

28. Dai W, Zhang B, Jiang XM, Su H, Li J, et al. (2020) Structure-based design of antiviral drug candidates targeting the SARS-CoV-2 main protease. Science 368(6497): 1331-1335.

29. Shi S, Qin M, Cai Y, Liu T, Shen B, et al. (2020) Characteristics and clinical significance of myocardial injury in patients with severe coronavirus disease 2019. European heart journal 41(22): 2070-2079.

30. Sanders JM, Monogue ML, Jodlowski TZ, Cutrell JB (2020) Pharmacologic treatments for coronavirus disease 2019 (COVID-19): a review. Jama 323(18): 1824-1836.

31. Pushpakom S, Iorio F, Eyers PA, Escott KJ, Hopper S, et al. (2019) Drug repurposing: progress, challenges and recommendations. Nature reviews Drug discovery 18(1): 41-58.

32. Li G, Clercq ED (2020) Therapeutic options for the 2019 novel coronavirus (2019-nCoV). Nature reviews Drug discovery 19(3): 149-150.

33. Andersen PI, Ianevski A, Lysvand H, Vitkauskiene A, Oksenych V, et al. (2020) Discovery and development of safe-in-man broad-spectrum antiviral agents. International Journal of Infectious Diseases 93: 268-276.

34. Guy RK, Dipaola RS, Romanelli F, Dutch RE (2020) Rapid repurposing of drugs for COVID-19. Science 368(6493): 829-830

35. Roden DM, Harrington RA, Poppas A, Russo AM (2020) Considerations for drug interactions on QTc in exploratory COVID-19 treatment. Circulation 141(24): e906-e907.

36. Yang X, Yu Y, Xu J, Shu H, Xia J, et al. (2020) Clinical course and outcomes of critically ill patients with SARS-CoV-2 pneumonia in Wuhan, China: a single-centered, retrospective, observational study. The Lancet Respiratory Medicine 8(5): 475-481.

37. Naicker S, Yang CW, Hwang SJ, Liu BC, Chen JH, et al. (2020) The novel coronavirus 2019 epidemic and kidneys. Kidney International 97(5): 824-828.

38. Cheng Y, Luo R, Wang K, Zhang M, Wang Z, et al. (2020) Kidney disease is associated with in-hospital death of patients with COVID-19. Kidney international 97(5): 829-838

39. Li Z, Wu M, Yao J, Gou J, Liao X, et al. (2020) Caution on kidney dysfunctions of COVID-19 patients. MedRxiv.

40. Mohamed MMB, Lukitsch I, Torres-Ortiz AE, Walker JB, Varghese V, et al. (2020) Acute kidney injury associated with coronavirus disease 2019 in urban New Orleans. Kidney360 1(7): 614-622.

41. Wang D, Hu B, Hu C, Zhu F, Liu X, et al. (2020) Clinical characteristics of 138 hospitalized patients with 2019 novel coronavirus-infected pneumonia in Wuhan, China. Jama 323(11): 1061-1069.

42. Chen N, Zhou M, Dong X, Qu J, Gong F, et al. (2020) Epidemiological and clinical characteristics of 99 cases of 2019 novel coronavirus pneumonia in Wuhan, China: a descriptive study. The lancet 395(10223): 507-513. 
43. Yang X, Yu Y, Xu J, Shu H, Xia J, et al. (2020) Clinical course and outcomes of critically ill patients with SARS-CoV-2 pneumonia in Wuhan, China: a single-centered, retrospective, observational study. The Lancet Respiratory Medicine 8(5): 475-481.

44. Guan WJ, Ni ZY, Hu Y, Liang WH, Ou CQ, et al. (2020) Clinical characteristics of coronavirus disease 2019 in China. New England journal of medicine 382(18): 1708-1720.
45. Ronco C, Navalesi P, Vincent JL (2020) Coronavirus epidemic: preparing for extracorporeal organ support in intensive care. The Lancet Respiratory Medicine 8(3): 240-241.

46. Adapa S, Chenna A, Balla M, Merugu GP, Koduri NM, et al. (2020) COVID-19 pandemic causing acute kidney injury and impact on patients with chronic kidney disease and renal transplantation. Journal of clinical medicine research 12(6): 352-361. 